\title{
Activity as a function of diet: I. Spontaneous activity ${ }^{\prime}$
}

G. H. COLLIER, R, L. SQUIBB AND FLORENCE JACKSON

RUTGERS, THE STATE UNIVERSITY

\begin{abstract}
Abstraet
Rats fed isocaloric diets varying in percentage protein showed the highest level of activity on a low protein diet and the lowest level of activity on a high protein diet. Thus dietary imbalances similar to deficiencies may be motivational.
\end{abstract}

\section{Problem}

Dietary deficiencies may result from any number of deviations from so-called balanced rations. For example, (1) the total caloric intake may be below that required for maintenance and growth; (2) an essential nutrient (s) may be missing; or (3) an essential (s) may be present in abnormal quantities. The first two types of deficiencies have been shown to motivate behavior by increasing both spontaneous and relevant activity. The third type, usually described as dietary imbalance, has received relatively little attention. In the study reported here, spontaneous activity was evaluated in rats fed isocaloric diets complete in all essentials and containing varying amounts of balanced protein.

\section{Procedures and Results}

Three isocaloric diets containing 13.8, 21.3 (normal controls), and $41.3 \%$ crude protein were used; each contained 4.8 calories per gram of diet, and the known requirements of the rat for minerals, vitamins and other essentials. Food and water were constantly available.

Three groups of three weanling rats each were matched on the basis of their average number of wheel turns (WT) per day over a three-day period. The experimental diets were then introduced and continued for 40 days at which time the diets of the high and low protein groups were interchanged and the experiment continued for an additional 20 days.

Figure 1 shows the number of WT per block of four days. Introduction of the new diets caused an immediate increase in the activity of the low protein group; after 10 days this declined somewhat but was still significantly above that of the normals (controls) at the end of the experiment. The activity of the high protein animals consistently fell below the normal protein group. Following the interchange of diets the previously high and now low protein fed group showed a rapid rise in activity; the previously low now high protein fed animals showed a decline.

Food and water intakes are presented in Fig. 2. The low protein animals showed a substantial increase in diet intake during the period of high activity, while the intakes of the normal and high protein animals were similar. As might be expected, the high protein group consumed more water than the other groups.

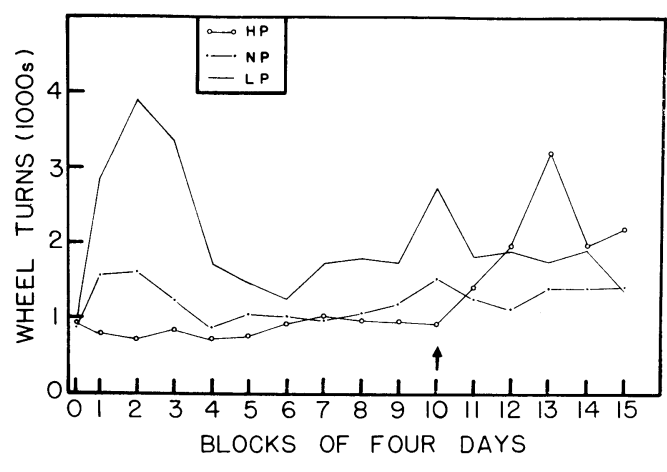

Fig. 1. Wheel turns as a function of diet. Arrow indicates interchange of high and low protein diets.

\section{Diseussion}

The classic view of spontaneous activity, first presented by Sherrington (1900), was that it was a reflex sensitized by deprivation which increased the probability of an animal finding food. Wald \& Jackson (1944) added an ecological corollary stating that the dispersion resulting from such "random" activity reduced the feeding pressure on the home range. Two derivative concepts were that activity was a measure of the activation effects of drive, and the view of Campbell \& Sheffield (1953) that increased activity resulted from lowered thresholds associated with deprivation. In the experiment reported

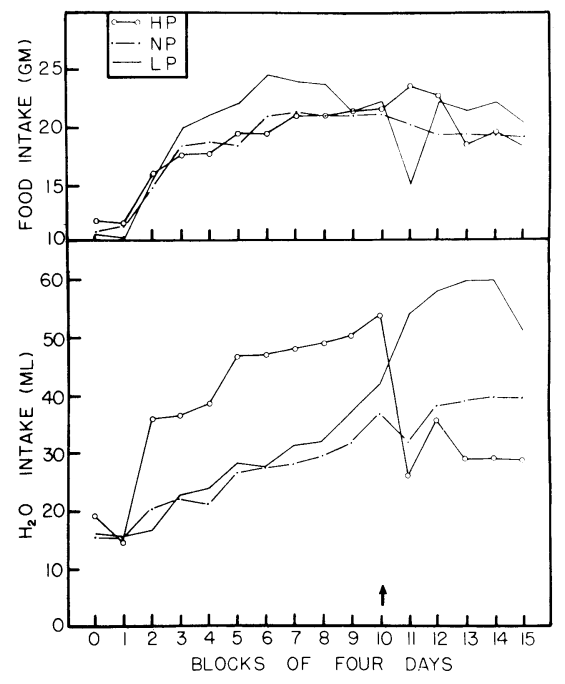

Fig. 2. Food and water intake as a function of diet. Arrow indicates interchange of high and low protein diets. 
here, two opposed deficiencies or imbalances were produced; one resulted in more and the other in less activity, rather than the predicted increase in both. The actual correlation obtained was an increase in activity with each decrease in ratio of protein to total calories of the diet.

A second class of hypotheses results from those who have viewed spontaneous activity as playing a role in the internal rather than the external economy of the organism. Brobeck (1945), for example, regarded such activity as a means of thermal regulation, a result of those conditions which tend to lower body temperature. The fact that in our experiment the diet which produced the highest activity led to a higher body temperature (Collier, Squibb, \& Jackson, 1965), and the diet which produced the lowest activity lower body temperature would contradict this hypothesis.

A similar hypothesis, contradicted by the present data, is that spontaneous activity represents an alternative way of disposing of the specific dynamic action (SDA) (e. g., Hartsook \& Hershberger, 1963) of the diet. Nutritional studies have shown that the SDA increases with degree of imbalance, which would lead to the prediction, again, that both the high and low protein fed rats would be more active than the normals.

A third possibility is that spontaneous activity plays some role in the regulation of food intake and/or body composition. In the present experiment the greater activity initiated by the low protein diet led to an in- creased rate of metabolism and consequently a higher level of food intake, thus increasing the gm of protein consumed per gm of body weight. The relatively lower activity level of the animals fed the high protein diet may be due to the fact that the energy requirement must be met through the least efficient process, namely, conversion of protein to glucose which is usually accompanied by a greater than normal production of uria. Concurrent behavioral, physiological and biochemical observations now in progress may shed light on this problem.

\section{References}

Brobeck, J. R. Effects of variations in activity, food intake and environmental temperature on weight gain in the albino rat. Amer. J. Physiol., 1945, 143, 1-5.

Campbell, B. A., \& Sheffield, F. D. Relation of random activity to feed deprivation. J. comp. physiol. Psychol., 1953, 46, 320-322.

Collier, G. H., Squibb, R. L., \& Jackson, Florence. Activity as a function of diet: II. Instrumental activity. Psychon. Sci., 1965, 3, 175-176.

Hartsook, E. W., \& Hershberger, T. Y. Influence of low, intermediate and high levels of dietary protein on heat production of rats. J. Nutrition, 1963, 81, 209-217.

Sherrington, C. S. Cutaneous sensation. In E. A. Schaeffer (Ed.), Textbook of physiology. New York: MacMillan, 1900

Wald, G., \& Jackson, B. Activity and nutritional deprivation. Proc. Acad. Sci., Wash., 1944, 30, 255-263.

\section{Note}

1. The work was supported in part by grant $\mathrm{MH} 10252$ from the United States Public Health Service, National Institute of Mental Health. 